\title{
Therapies for Smoking Cessation: A Meta-analysis of Double-blind Randomized Controlled Trials
}

Dipika Dabas

\begin{abstract}
Background: Several placebo-controlled randomized trials have shown a substantial effect of many products used for smoking cessation. The trials have revealed results by performing either a direct or indirect comparisons. The present metaanalysis is an endeavor to compare the effect of the currently available and widely used seven pharmacological interventions as an aid to smoking cessation.
\end{abstract}

Methods: The databases like MEDLINE, EMBASE and the Cochrane reviewed published trials were investigated and further screened to meet the inclusion criteria. For example, only double-blind randomized controlled trials were included who have validated the results of abstinence at 6 and 12 months biochemically.

Results: A total of 69 trials were identified with a total number of 32,908 participants. Out of seven therapies chosen for the analysis, six were found to be more effective than placebo, the odds ratio (OR) for varenicline was $2.41,95 \% \mathrm{Cl} 1.91-3.12$, for nicotine spray (OR) $2.37,95 \% \mathrm{Cl} 1.12-5.13$, bupropion with (OR) $2.07,95 \% \mathrm{Cl} 1.73-2.55$, transdermal nicotine patch (OR) 2.07, $95 \% \mathrm{Cl} 1.69-2.62$, nicotine tablet (OR) 2.06, 95\% Cl 169-2.62, and for gum (OR) $1.71,95 \% \mathrm{Cl} 1.35-2.21$. Though OR of 2.71 in case of nicotine inhaler favors its effectiveness over placebo, but this result remained inconclusive as the $95 \% \mathrm{Cl}$, in this case, includes unity $(0.95-5.43)$. On the contrary, when all the seven interventions were analyzed by putting them all together, all of them were found to be effective than a placebo. When varenicline was compared against bupropion (control arm), the former was found to be superior in its effect on smoking cessation than the latter with (OR 2.18, $95 \mathrm{Cl} \%$ 1.09-4.08).

Interpretation: The interventional products used for smoking abstinence for 6 and 12 months, namely varenicline, bupropion, and 5 nicotine replacement therapies like nicotine gum, inhaler, transdermal patch, tablet, and lozenges were all found to be effective than placebo.

Keywords: Double blind, Nicotine spray, Smoking, Therapy.

How to cite this article: Dabas D. Therapies for Smoking Cessation: A Meta-analysis of Double-blind Randomized Controlled Trials. J Health Sci Res 2018;9(2):49-56.

Source of support: Nil

Conflict of interest: None

Senior Manager

Department of Health, Research and Wellness, Vipul MedCorp, Gurugram, Haryana, India

Corresponding Author: Dipika Dabas, Senior Manager, Department of Health, Research and Wellness, Vipul MedCorp, Gurugram, Haryana, India, e-mail: dipikadabas@gmail.com

\section{INTRODUCTION}

Smoking is considered the prime cause of preventable mortality. ${ }^{49}$ Although smoking cessation is a challenging task, yet researcher fraternity strives and put considerable effort into identifying various tools to help smokers in quitting smoking habits. ${ }^{41}$ Out of every two chronic smokers, one is expected to die because of smokingrelated health consequences. ${ }^{10}$ The prevalence rate of smoking in Maori (adults 15 years and above) is very high $(46 \%)$.

Maori women as compared to Maori men have a higher rate of smoking ( $50 \%$ in females and $40 \%$ in men) and the smoking rate in Maori women of childbearing age (15-39 years) is even higher (61\%). ${ }^{44}$ Furthermore, this incidence has not declined over time among Maoris as compared to the decline observed in the general population. ${ }^{44}$ Thus, the interventions for smoke prevention in Maoris need to be addressed for nicotine dependence which must include an all-time support and an effective way of delivery of smoking cessation program which is culturally appropriate and also ensures the inclusion of all the members of the whanau. ${ }^{20}$ Hence, giving Maoris a choice of alternative treatment options is the dire need of the era. ${ }^{34}$ Smoking cessation has a potential effect on the reduction of morbidity and healthcare costs related to the treatment of smoking-induced conditions. ${ }^{41}$

Nowadays, several pharmacological therapies are available as an aid for the cessation of smoking habits like bupropion, varenicline, and nicotine replacement therapy (NRT). ${ }^{41}$

NRT is the most commonly used intervention used for smoking cessation, and it is one of the frequently available over the counter (OTC) product for the consumers. ${ }^{53} \mathrm{It}$ is also recommended as one of the safest interventional therapy to not only the general population but also to the high-risk groups like pregnant and lactating women, adolescence and smokers with cardiovascular anomalies. ${ }^{42}$ The cessation rate, improved by NRT at a duration of one year is roughly $70 \%$ with 1.70 odds ratio and 95 confidence interval (CI) as $1.55-1.88 .^{21,42,53}$ Under NRT, several formulations namely transdermal patch, nasal sprays, tablets, gum, inhaler, and lozenges have been marketed. It works by a mechanism wherein it replaces nicotine which is either obtained by smoking or by other means and thus helps in dealing with the withdrawal 
symptoms and cravings that are generated as a result of quitting smoking.

More recently, varenicline has been demonstrated as an effective agent with a unique mechanism of action for improving the rates of smoke cessation. ${ }^{18,32,47,58 \text {, }}$

Varenicline stimulates dopamine and thus reduces craving and withdrawal symptoms. The nicotine receptors are also blocked by this drug which then prevents the release of dopamine which is associated with the consumption of nicotine. ${ }^{47,48}$

Another agent, bupropion is gaining attention nowadays as an antidepressant therapy for assisting in smoking cessation. ${ }^{48}$ There is a lack of consensus among clinicians and researchers in finding the safest and the most effective therapy as some view varenicline while other refer NRT as the most effective aid for the smoking cessation. Consequently, there is a need to compare the effectiveness of all these interventions available as an aid for the cessation of smoking.

The meta-analysis of placebo-controlled randomized trials is being undertaken for viewing the effectiveness of 7 pharmacological interventions that have been approved and are being currently in use. Thus the objective of this article is first, to compare directly varenicline and bupropion by analyzing the trials which used these therapies as treatment arms; secondly, to undertake an analysis to compare all the seven interventions by viewing the results of individual studies.

\section{METHODS}

\section{Search Strategy}

The databases like MEDLINE, EMBASE as well as Cochrane library were searched and the report of 7 interventional studies in the English language was identified for this analysis. The keywords like "smoking", "varenicline", "bupropion", nicotine inhaler", "nicotine gum", "transdermal nicotine patch", "nicotine tablet", "inhaler" and "random control trials" were used for this search.

\section{Study Selection}

The only placebo-controlled double-blind, randomized control trials, which validated the abstinence from smoking at 6 and 12 months biochemically have been included in this meta-analysis. The trials irrespective of the settings (hospitals, clinics) and adjunctive support therapy (counseling) were also included in this analysis. Some of the factorial designed trials were included as separate trials as long as there counter placebos were appropriately used.

All the unblinded studies were excluded from the analysis. Moreover, the studies that had the subjects suffering from some chronic ailments were also excluded.
We made an effort to limit our study to only doubleblinded placebo controlled trials which itself suggests that a strict inclusion criteria has been used for this analysis.

\section{Classification of Outcomes}

The abstinence for this analysis is defined as either point prevalence or continuous abstinence wherein the later means non-smoking from the baseline quit date until the follow-up period and the point prevalence means abstinence over the given period.

The criterion for the outcome to be included for the analysis was defined on the basis of following grades: 1) Continuous abstinence and point prevalence of one year, 2) Continuous abstinence and point prevalence of six months. The assessment of the outcomes was based on the intent-to-treat principle.

We identified 69 placeboes controlled RCT's through the literature research. All these were meeting the inclusion criteria (Flow chart 1). We found a total of 16 trials of bupropion with a total of 6653 subjects, 13 trials of varenicline with 3395 subjects, 22 trials using nicotine gum with 5200 patients, 4 trial each of inhaler with 976 subject and nasal spray with 887 participants (Figs 1 and 2), 6 studies of nicotine tablet with 2306 subjects (Fig. 3) and 30 trials of transdermal nicotine patch with 14459 participants. The comparison figures of point prevalence of abstinence at 6 and 12 months were 45 and 40, respectively whereas for continuous abstinence at 6 and 12 months were 49 and 55, respectively.

The pooled data and forest plot for each intervention as per the predefined criterion are depicted for bupropion (Fig. 4), nicotine gum in Figures 5 and 6 for transdermal, Figure 7 for varenicline, Figure 8 for comparisons in between the different therapies and Figure 9 is depicting the comparison between varenicline and bupropion. The data for these therapies were adjusted in different ways. For example, the data for bupropion was adjusted for the duration and dosage of the treatment, whereas for

Flow chart 1: Inclusions and exclusions

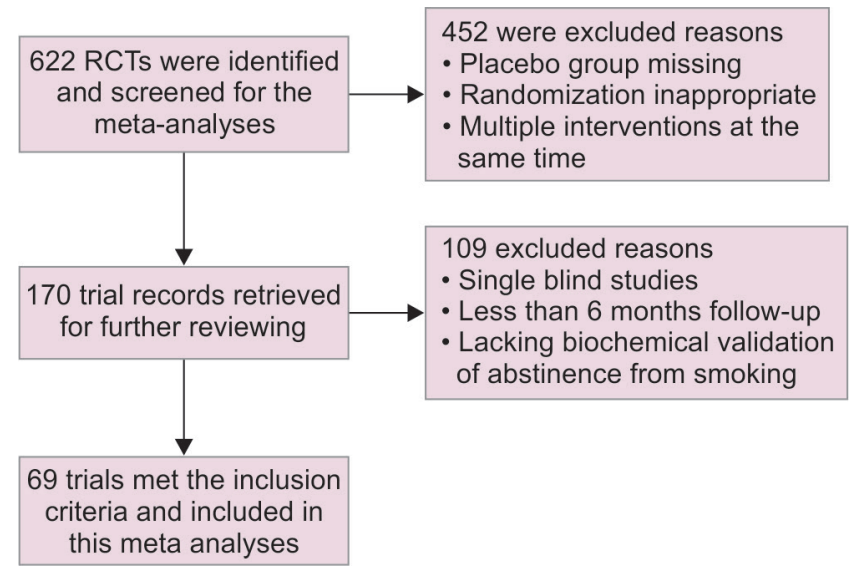


nicotine gum and tablet, the adjustment was done for dosage only. On the other hand, the data for transdermal nicotine patch was adjusted on the basis of two factors: One, for continuous versus tapered treatment and second, for 16 hours versus 24-hour treatment.

It was found that all therapies used for smoking cessations were efficacious than placebo except nicotine inhalers where, although, the odd ratio 2.17 favored it over placebo but as the $95 \%$ confidence interval included unity (95\% CI 0.95-5.43), the results remained inconclusive. However when all of these interventions were put together in a meta-analysis, all of these 7 therapies were found to be more effective than placebo (Fig. 5).

\section{Statistical Analysis}

To deal with heterogeneity of the variables like metho dologies used in the trials, settings used for the trials, the intensity of the adjunct support therapy used along

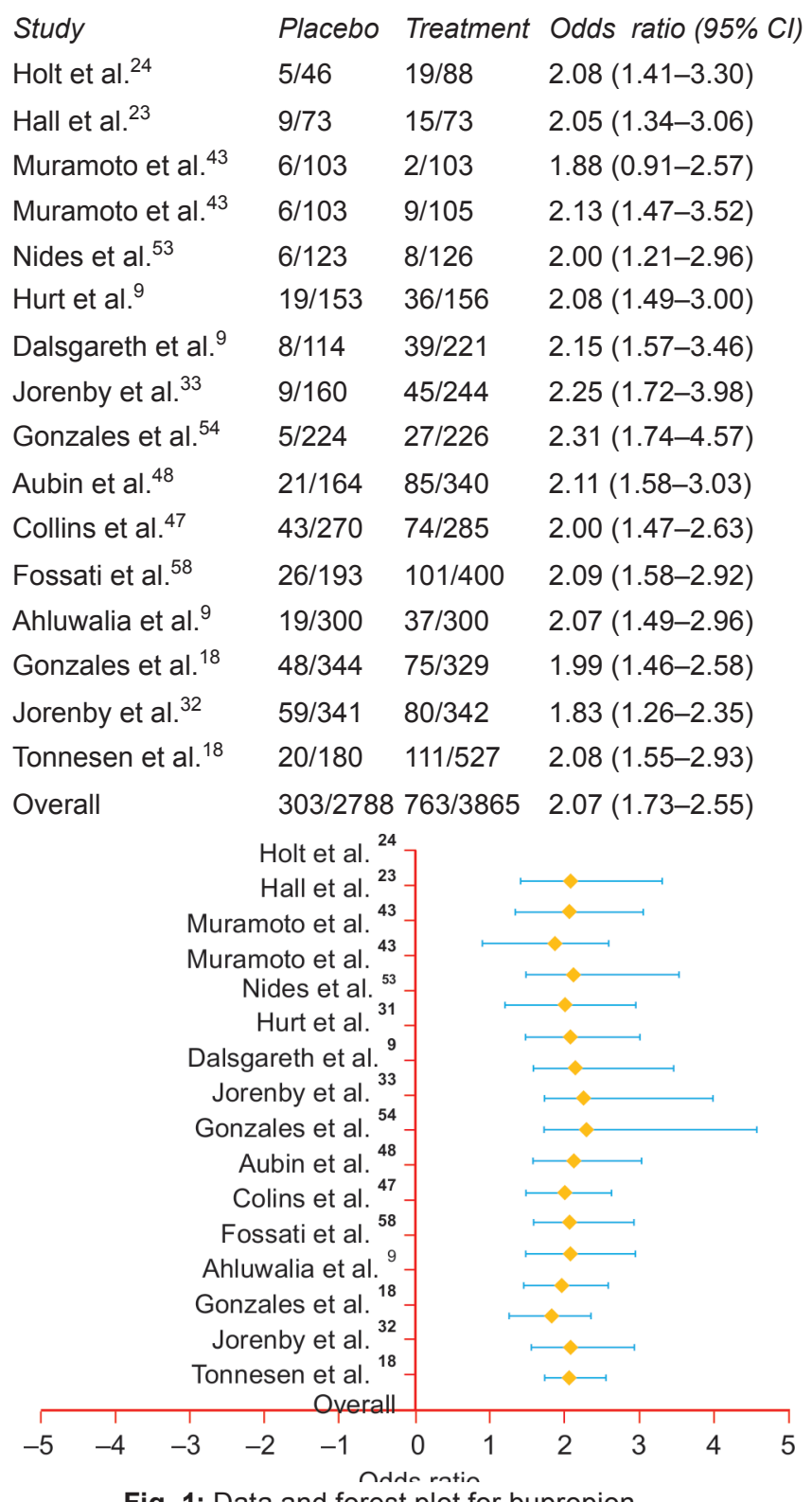

Fig. 1: Data and forest plot for bupropion with these therapies and the differences in the patient's demography, meta-regression analysis was used. There was a likelihood of achieving abstinence from smoking in varied logarithms in both control and treatment groups in not only with-in the study but also in between the studies, but we assumed that the pattern of the odds ratio would follow the normal distribution graph for each outcome within the study, where the mean treatment effect would be considered as the mean and the differences in the odds-ratio between the trials as the variance.

On this prior assumed normal distribution, for each mean treatment effect, a mean of 0 and a variance

\begin{tabular}{|c|c|c|c|}
\hline Study & Placebo & Treatment & Odds ratio $(95 \% \mathrm{Cl}$ \\
\hline Schneider et al. ${ }^{55}$ & $3 / 23$ & $1 / 13$ & $1.53(0.67-3.19)$ \\
\hline Jarvik et al. ${ }^{35}$ & $4 / 23$ & $7 / 25$ & $1.73(0.89-3.59)$ \\
\hline Schneider et al. ${ }^{55}$ & $6 / 30$ & $9 / 30$ & $1.70(0.89-3.40)$ \\
\hline Hall et al. ${ }^{28}$ & $7 / 34$ & $12 / 35$ & $1.78(0.96-3.52)$ \\
\hline Hall et al. ${ }^{28}$ & $7 / 34$ & $18 / 36$ & $2.19(1.24-4.70)$ \\
\hline Tonnesen et al. ${ }^{59}$ & $12 / 53$ & $23 / 60$ & $1.86(1.09-3.43)$ \\
\hline Jarvis et al. ${ }^{37}$ & $8 / 58$ & $18 / 58$ & $2.04(1.18-4.00)$ \\
\hline Malcolm et al. ${ }^{46}$ & $3 / 63$ & $17 / 73$ & $2.42(1.35-5.52)$ \\
\hline Herrera et al. ${ }^{27}$ & $17 / 78$ & $37 / 76$ & $2.40(1.46-4.44)$ \\
\hline Blondal et al. ${ }^{5}$ & $22 / 90$ & $30 / 92$ & $1.59(0.97-2.60)$ \\
\hline Areechon et al. ${ }^{3}$ & $37 / 101$ & $56 / 98$ & $2.02(1.31-3.31)$ \\
\hline Jamrozik et al. ${ }^{36}$ & $8 / 99$ & 10/101 & $1.54(0.81-2.82)$ \\
\hline Hall et al. ${ }^{25}$ & $25 / 103$ & $21 / 98$ & $1.19(0.67-1.93)$ \\
\hline Hjalmarson et al. ${ }^{26}$ & $16 / 99$ & $29 / 106$ & $1.82(1.12-3.08)$ \\
\hline Cooper et al. ${ }^{7}$ & $15 / 148$ & $17 / 146$ & $1.43(0.81-2.39)$ \\
\hline Fortmann et al. ${ }^{14}$ & $44 / 148$ & $33 / 152$ & $0.93(0.56-1.52)$ \\
\hline Hughes et al. ${ }^{22}$ & $6 / 105$ & $23 / 210$ & $1.82(1.04-3.48)$ \\
\hline Fee et al. ${ }^{13}$ & $15 / 172$ & $23 / 180$ & $1.62(0.97-2.71)$ \\
\hline Garvey et al. ${ }^{17}$ & $13 / 203$ & $27 / 202$ & $1.91(1.20-3.25)$ \\
\hline Garvey et al. ${ }^{17}$ & $13 / 203$ & $26 / 203$ & $1.85(1.15-3.14)$ \\
\hline Killen et al. ${ }^{38}$ & $56 / 309$ & $57 / 301$ & $1.21(0.82-1.74)$ \\
\hline Campbell et al. ${ }^{6}$ & $11 / 424$ & $19 / 412$ & $1.75(1.04-3.09)$ \\
\hline Overall & $335 / 2397$ & $513 / 2707$ & $1.71(1.35-2.21)$ \\
\hline
\end{tabular}

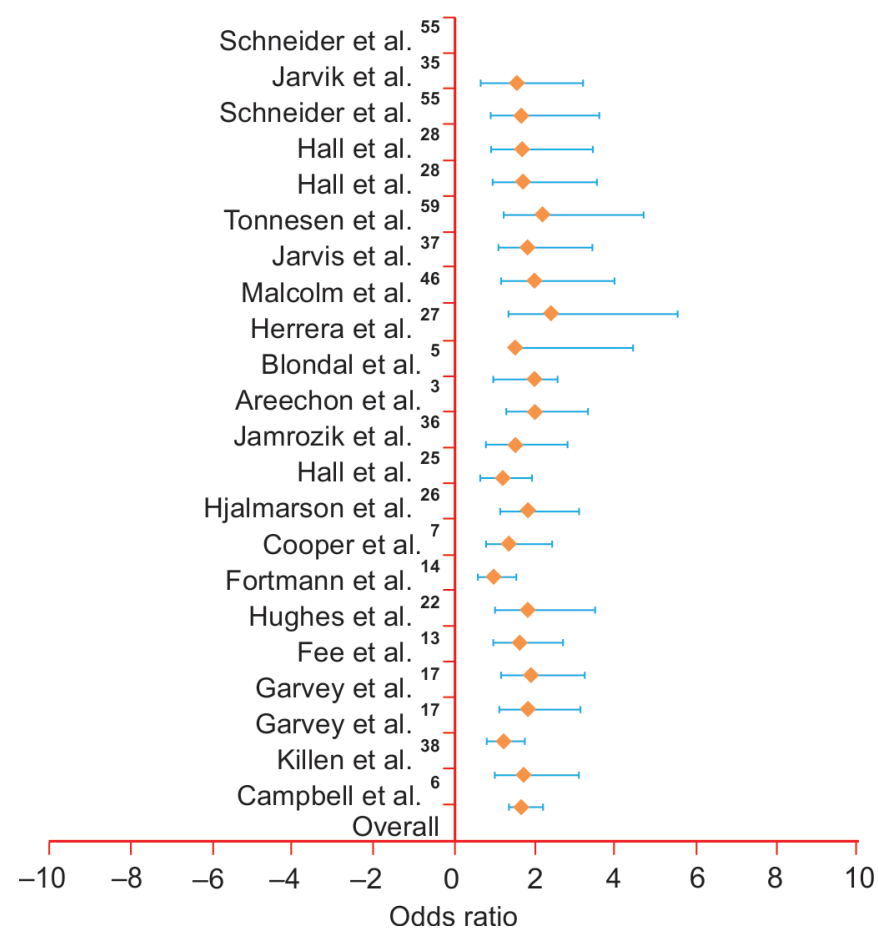

Fig. 2: Data and forest plot for nicotine gum 


\begin{tabular}{|c|c|c|c|}
\hline Study & Placebo & Treatment & Odds ratio $(95 \% \mathrm{Cr}$ \\
\hline ICRF GPRG $^{12,51}$ & $53 / 844$ & $76 / 842$ & $1.67(1.21-2.21)$ \\
\hline Daughton et al. ${ }^{11}$ & $3 / 25$ & $6 / 25$ & $1.99(1.27-3.47)$ \\
\hline Daughton et al. ${ }^{11}$ & $3 / 25$ & $8 / 27$ & $2.12(1.38-3.90)$ \\
\hline Fiore et al. ${ }^{15}$ & $9 / 43$ & $15 / 44$ & $1.94(1.24-3.17)$ \\
\hline Glavas et al. ${ }^{16}$ & $9 / 56$ & $13 / 56$ & $1.88(1.16-2.94)$ \\
\hline Fiore et al. ${ }^{15}$ & $4 / 55$ & $10 / 57$ & $2.02(1.29-3.50)$ \\
\hline Paoletti et al. ${ }^{50}$ & $5 / 60$ & $17 / 60$ & $2.20(1.47-4.00)$ \\
\hline Westman et al. ${ }^{63}$ & $2 / 80$ & $16 / 78$ & $2.35(1.56-4.84)$ \\
\hline Abelin et al. ${ }^{1,2}$ & $12 / 99$ & $22 / 100$ & $1.96(1.31-3.10)$ \\
\hline Killen et al. ${ }^{40}$ & $15 / 104$ & $21 / 103$ & $1.83(1.16-2.75)$ \\
\hline Killen et al. ${ }^{40}$ & $11 / 108$ & $15 / 109$ & $1.82(1.12-2.78)$ \\
\hline Sachs et al. ${ }^{57}$ & $10 / 107$ & $28 / 113$ & $2.19(1.51-3.73)$ \\
\hline Kornitzer et al. ${ }^{39}$ & $10 / 75$ & $19 / 150$ & $1.69(0.96-2.52)$ \\
\hline Hurt et al. ${ }^{31}$ & $17 / 120$ & $33 / 120$ & $2.04(1.41-3.18)$ \\
\hline Hughes et al. ${ }^{30}$ & $6 / 160$ & $16 / 119$ & $2.47(1.66-4.62)$ \\
\hline Tonnesen et al. ${ }^{62}$ & $3 / 144$ & $16 / 154$ & $1.70(1.19-2.33)$ \\
\hline Richmond et al. ${ }^{52}$ & $14 / 153$ & $29 / 154$ & $2.03(1.39-3.18)$ \\
\hline Hughes et al. ${ }^{30}$ & $6 / 160$ & $4 / 160$ & $1.52(0.82-2.26)$ \\
\hline Hughes et al. ${ }^{30}$ & $6 / 160$ & $12 / 160$ & $1.97(1.29-3.15)$ \\
\hline Daughton et al. ${ }^{8}$ & $16 / 185$ & $27 / 184$ & $1.91(1.28-2.86)$ \\
\hline Jorenby et al. ${ }^{33}$ & $9 / 160$ & $24 / 244$ & $1.92(1.25-3.00)$ \\
\hline TNSG61 & $31 / 253$ & $65 / 249$ & $1.49(1.08-1.97)$ \\
\hline TNSG61 & $31 / 253$ & $46 / 254$ & $1.71(1.27-2.19)$ \\
\hline Gourlay et al. ${ }^{19}$ & $4 / 314$ & $5 / 315$ & $1.86(1.09-3.05)$ \\
\hline Hays et al. ${ }^{29}$ & $9 / 322$ & $18 / 321$ & $1.97(1.30-3.15)$ \\
\hline Stapleton et al. ${ }^{56}$ & $19 / 400$ & $77 / 800$ & $2.01(1.45-2.98)$ \\
\hline Tonessen et al. ${ }^{60}$ & $71 / 714$ & $98 / 715$ & $1.89(1.44-2.43)$ \\
\hline Tonnesen et al. ${ }^{60}$ & $71 / 714$ & $114 / 715$ & $2.25(1.51-4.27)$ \\
\hline Tonnesen et al. ${ }^{60}$ & $71 / 714$ & $110 / 715$ & $2.27(1.67-3.30)$ \\
\hline Tonnesen et al. ${ }^{60}$ & $71 / 714$ & $84 / 716$ & $1.95(1.49-2.51)$ \\
\hline Overall & $342 / 4581$ & $1044 / 7850$ & $1.95(1.65-2.34)$ \\
\hline
\end{tabular}

Study

Nides et al. ${ }^{47}$

Nides et al. ${ }^{47}$

Nides et al. ${ }^{47}$

Tsai et al. ${ }^{44}$

Oncken et al. ${ }^{42}$

Oncken et al. ${ }^{42}$

Nakamura et al. ${ }^{45}$

Nakamura et al. ${ }^{45}$

Jorenby et al. ${ }^{32}$

Gonzales et al. ${ }^{18}$

Overall
Oncken et al. ${ }^{42}$

Oncken et al. ${ }^{42}$

Nakamura et al. ${ }^{45}$

$\begin{array}{lll}\text { Placebo } & \text { Treatment } & \text { Odds ratio (95\% Crl) } \\ 6 / 123 & 18 / 125 & 2.61(1.91-4.64) \\ 6 / 123 & 7 / 126 & 2.23(1.28-3.09) \\ 6 / 123 & 10 / 126 & 2.33(1.49-3.38) \\ 27 / 124 & 59 / 126 & 2.54(1.90-3.82) \\ 5 / 129 & 25 / 129 & 2.45(1.77-3.80) \\ 5 / 129 & 24 / 129 & 2.42(1.74-3.67) \\ 5 / 129 & 33 / 130 & 2.68(1.99-4.85) \\ 5 / 129 & 24 / 130 & 2.42(1.73-3.69) \\ 35 / 154 & 47 / 153 & 2.22(1.45-2.96) \\ 35 / 154 & 56 / 155 & 2.40(1.72-3.28) \\ 35 / 154 & 51 / 155 & 2.29(1.56-3.07) \\ 59 / 341 & 105 / 344 & 2.31(1.72-2.98) \\ 48 / 344 & 99 / 352 & 2.41(1.84-3.19) \\ 180 / 1215558 / 2180 & 2.41(1.91-3.12)\end{array}$

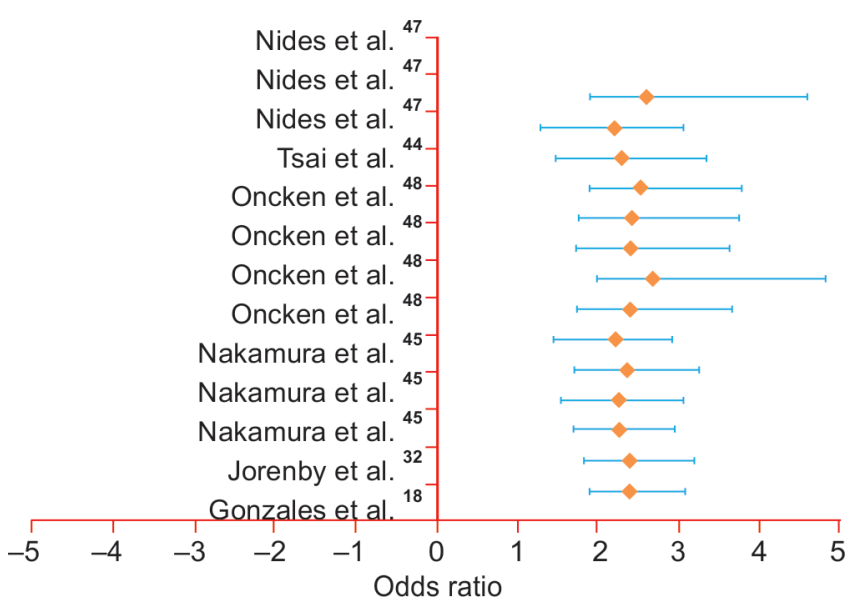

Fig. 4: Data and forest plot for varenicline

Pharmacotherapy

Bupropion

Odds ratio $(95 \% \mathrm{Crl})$

Daughton et al.

Fiore et al.

Glavas et al.

Fiore et al.

Paoletti et al.

Westman et al.

Abelin et al.

Killen et al.

Killen et al.

Sachs et al.

Kornitzer et al.

Hurt et al.

Hughes et al.

Tonnesen et al.

Richmond et al.

Hughes et al. ${ }^{30}$

Hughes et al. ${ }^{30}$

Daughton et al.

Jorenby et al. ${ }^{33}$ TNSG $^{6}$ TNSG

Gourlay et al.

Hays et al. ${ }^{20}$

Stapleton et al. ${ }^{56}$

Tonessen et al.

Tonnesen et al.

Tonnesen et al.

Tonnesen et al.

Overall

Bupropion
Nicotine gum
Nicotine inhaler
Nicotine nasal spray
Nicotine tablet
Varenicline

$2.12(1.76-2.56)$

$1.65(1.37-2.01)$

$2.18(1.38-3.45)$

$2.37(1.57-3.60)$

$1.88(1.60-2.22)$

$2.06(1.47-2.87)$

$2.55(1.99-3.24)$

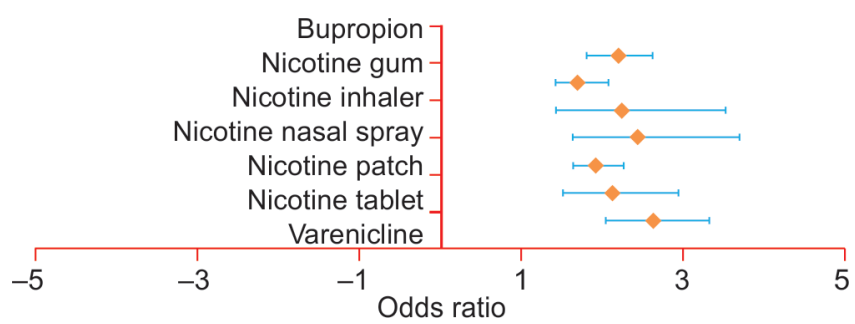

Fig. 5: Data and forest plot for pharmacotherapies

$\begin{array}{llll}\text { Study } & \text { Placebo } & \text { Treatment } & \text { Odds ratio (95\% Crl) } \\ \text { Nides et al. }{ }^{47} & 6 / 123 & 18 / 125 & 2.73(1.56-6.46) \\ \text { Nides et al. }{ }^{47} & 6 / 123 & 7 / 126 & 1.79(0.65-3.21) \\ \text { Nides et al. }{ }^{47} & 6 / 123 & 10 / 126 & 2.04(0.91-3.88) \\ \text { Jorenby et al. }^{4} & 59 / 341 & 105 / 344 & 2.13(1.53-2.96) \\ \text { Gonzales et al. }^{18} & 48 / 344 & 99 / 352 & 2.33(1.67-3.33) \\ \text { Overall } & 113 / 808 & 239 / 1073 & 2.18(1.09-4.08)\end{array}$

Fig. 3: Data and forest plot for transdermal nicotine 
Therapies for Smoking Cessation: A Meta-analysis of Double-blind Randomized Controlled Trials

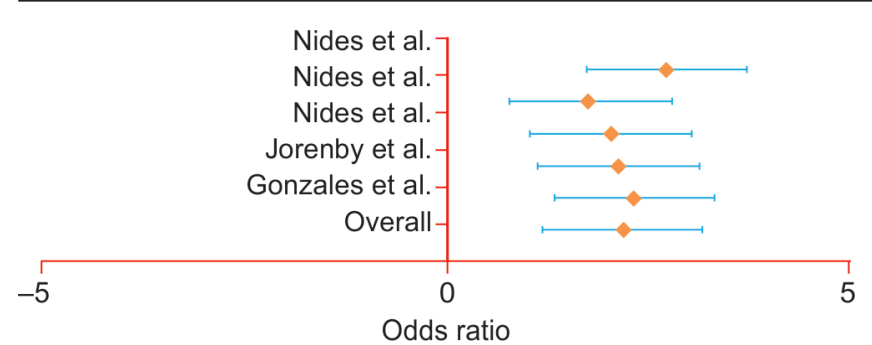

Fig. 6: Data and forest plot for varenicline versus bupropion

Trial Placebo Treatment Odds ratio (95\% Cl)

Tonnesen et al. ${ }^{60} \quad 7 / 141 \quad 22 / 145 \quad 2.53(1.46-6 / 02)$

Hjalmarson et al. ${ }^{26} \quad 22 / 124 \quad 35 / 145 \quad 2.01(1.18-3.39)$

Schneider et al. ${ }^{55} \quad 9 / 111 \quad 15 / 112 \quad 2.03(1.00-3.90)$

Leischowet al. $^{43} \quad 6 / 110 \quad 12 / 110 \quad 2.16(1.06-4.68)$

Overall $\quad 44 / 486 \quad 84 / 490 \quad 2.17(0.95-5.43)$

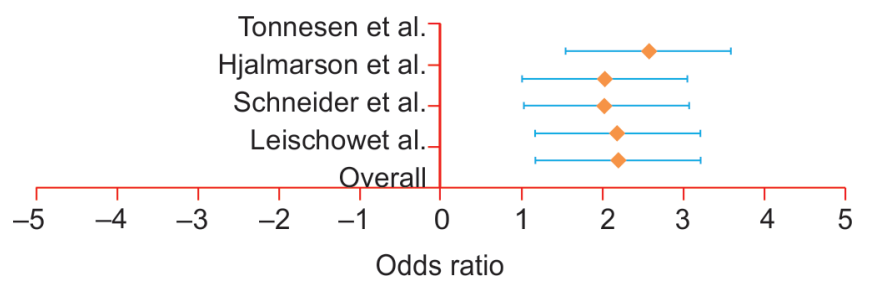

Fig. 8: Data and analysis of spray

of 1000000 were used and for placebo group, a mean of 0 and a variance of 10000 were used. Similarly, the same distribution was implied for the regression parameters.

The outcomes at 6 months and at 12 months plus the outcomes of point prevalence and continuous abstinence were pooled separately thereby, resulting in 4 models for each of the seven treatments investigated in this meta-analysis. The efficacy of the included therapies in the analyses was compared by using a single, large meta-analysis modal. A separate model for the odds ratio pertaining to the characteristics like type of therapy used, the age of the participants, sex, and mean a number of cigarettes smoked per day, was used for the analysis.

The ratio of the odds ratio was calculated between the interventions for comparing and creating the indicator variables for each of the therapy used in the analysis. A direct comparison was undertaken in this article for the products like varenicline and bupropion in those trials which used both of them as the treatment arms.

\section{Varenicline versus Bupropion}

When varenicline was compared indirectly in the hierarchal meta-analysis, we found that it is more effective than any other therapy but when a direct comparison was done with bupropion as an active arm in three of the trial, ${ }^{18,32,47}$ varenicline was also found to be far effective than the bupropion (OR 2.18, 95 CI 1.09-4.08) (Fig. 9). However, in the former case, it was difficult to draw any conclusion because attacks, were reported in the trial using bupropion.

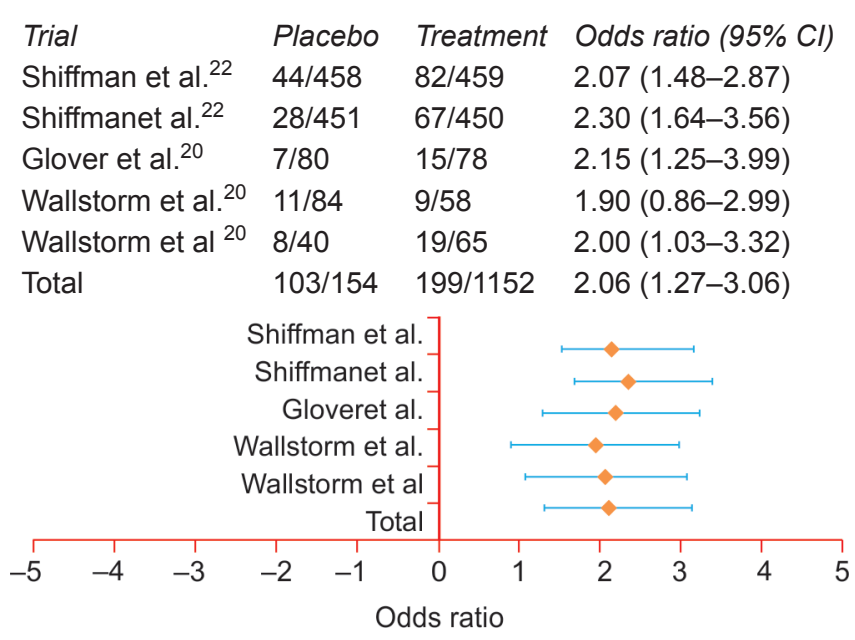

Fig. 7: Data and analysis of tablet

\begin{tabular}{|c|c|c|c|}
\hline Trial & Placebo & Treatment & Odds ratio $(95 \% \mathrm{Cl})$ \\
\hline Tonnesen et al. $^{52}$ & $7 / 141$ & $22 / 145$ & $2.53(1.46-6 / 02)$ \\
\hline Hjalmarson et al. ${ }^{26}$ & $22 / 124$ & $35 / 145$ & $2.01(1.18-3.39)$ \\
\hline Schneider et al. ${ }^{55}$ & $9 / 111$ & $15 / 112$ & $2.03(1.00-3.90)$ \\
\hline Leischow et al. ${ }^{43}$ & $6 / 110$ & $12 / 110$ & $2.16(1.06-4.68)$ \\
\hline Overall & $44 / 486$ & $84 / 490$ & $2.17(0.95-5.43)$ \\
\hline $\begin{array}{r}\text { Tonnesen } \\
\text { Hjalmarson } \\
\text { Schneider } \\
\text { Leischow } \\
\text { O }\end{array}$ & $\begin{array}{l}\text { et al. } \\
\text { et al. } \\
\text { et al. } \\
\text { et al. } \\
\text { verall }\end{array}$ & 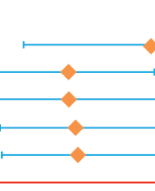 & \\
\hline-3 & -1 & $\begin{array}{ll}1 & 3 \\
\text { dds ratio } & \end{array}$ & 5 \\
\hline
\end{tabular}

Fig. 9: Data and analysis of inhaler

The small number of seizure attacks could be due to excluding all those who were at risk before undertaking randomization. Moreover, the definition used for adversarial effects in the trials also defers. For example, bupropion trial conducted by Jorenby et al., ${ }^{33}$ headache was reported as an adverse event by over $30 \%$ in those who were randomized to the placebo group and on the other hand the trial conducted by Ahluwalia et al., ${ }^{4}$ only $4 \%$ reported to have observed headache in the placebo randomized group. This heterogeneity in reporting of the adverse effect might be due to assigning them with different definition and assessment procedure.

Although the pharmacotherapies were found to be effective in smoking cessation but the number of subjects who showed abstinence during the follow-up period remained very low, for example, the point prevalence reported to be fewer than $30 \%$ by most of the trials and with continuous abstinence, this rate was found to be even lower. Consequently, additional research is required for developing new and improved pharmacotherapies for smoking cessation and future RCTs can focus on multiple ways to incorporate these therapies and agents.

This study has many limitations like, despite strict setting inclusion and exclusion criteria, the heterogeneity between the variables could not be ignored. For example, there were differences in the duration of treatment, 
dosages, and assessment of abstinence measures but when these outcomes were analyzed separately, similar results were observed.

Secondly, the trials chosen for the meta-analysis had healthy smoker subjects who can be easily motivated to quit smoking than the subjects who actually are diseased. Thus, it lacks the representativeness and so as the generalizability. Furthermore, the trials included in the meta-analysis have used those settings where dosages, the assessment, and patterns of use of these products can be controlled. Consequently, the effect of these therapies on the smokers remained poorly understood by the users in the actual world.

Thirdly, only trials published in the English language were included in this meta-analyses which could lead to selection biased, and fourthly, a number of statistical comparisons were been undertaken in this analysis for which no adjustment was done.

Finally, the integrity of the randomization process was fragmented as all those patients who died during the trial were excluded from the studies which may result in misinterpreting the results or underestimating the results.

\section{CONCLUSION}

With this meta-analysis, it was found that all the 7 pharmacotherapies namely varenicline, bupropion, and the 5 nicotine replacement therapies (nicotine gum, nicotine inhaler, nicotine tablet, nicotine inhaler, and transdermal nicotine patch) have an effective impact on cessation of smoking. Moreover, we also found that varenicline may have a superior and a better effect as compared to bupropion. Despite this result which is favoring these products in the promotion of smoking cessation, their true effect cannot be validated as the absolute count of the participants who showed abstinence at 12 months was quite low. Thus, new and improved agents for smoking cessation needs to be developed and researched along with identifying new strategies to find alternative and different ways of using the currently available agents.

\section{REFERENCES}

1. Abelin T, Buehler A, Muller P, et al. Controlled trial of transdermal nicotine patch in tobacco withdrawal. Lancet 1989;1:7-10.

2. Abelin T, Ehrsam R, Buhler-Reichert A, et al. Effectiveness of a transdermal nicotine system in smoking cessation studies. Methods Find Exp Clin Pharmacol 1989;11:205-214.

3. Areechon W, Punnotok J. Smoking cessation through the use of nicotine chewing gum: a double-blind trial in Thailand. ClinTher1988;10:183-186.

4. Ahluwalia JS, Harris KJ, Catley D, et al. Sustained-release bupropion for smoking cessation in African Americans: a randomized controlled trial. JAMA 2002;288:468-474.
5. Blondal T. Controlled trial of nicotine polacrile $\mathrm{x}$ gu $\mathrm{m}$ with supportive measures. Arch Intern Med 1989;149:1818-1821.

6. Campbell IA, Lyons E, Prescott RJ. Stopping smoking. Do nicotine chewing-gu mand postal encouragement add to doctors' advice. Practitioner 1987;231:114-117.

7. Cooper TV, Klesges RC, Debon MW, et al. A placebo controlled randomized trial of the effects of phenylpropanolamine and nicotine gum on cessation rates and post cessation weight gain in wo men. Addict Behav 2005;30:61-75.

8. Daughton D, Sus man J, Sitorius M, et al. Transdermal nicotine therapy and primary care. Importance of counseling, demographic, and participant selection factors on 1-year quit rates. The Nebraska Primary Practice Smoking Cessation TrialGroup. Arch Fam Med 1998;7:425-430.

9. Dalsgareth OJ, Hansen NC, Soes-Petersen U, et al. A multicenter, rando mized, double-blind, placebo- controlled, 6-month trial of bupropion hydrochloride sustained-release tablets as an aid to smoking cessation in hospital employees. Nicotine Tob Res 2004;6:55-61.

10. Doll R, Peto R, Wheatley K, Gray R, Sutherland I: Mortality in relation to smoking: 40 years' observations on male British doctors.BMJ 1994;309:901-911.

11. Daughton DM, Heatley SA, Prendergast JJ, et al. Effect of transdermal nicotine delivery as an adjunct to low-intervention smoking cessation therapy. A randomized, placebo-controlled, double-blind study. Arch Intern Med 1991;151:749-752.

12. Effectiveness of a nicotine patch in helping people stop smoking: results of a randomized trial in general practice. Imperial Cancer Research Fund General Practice Research Group. BMJ 1993;306:1304-1308.

13. Fee WM, Stewart MJ. A controlled trial of nicotine chewing gum in a smoking withdrawal clinic. Practitioner 1982; 226:148-151.

14. Fortmann SP, Killen JD, Telch MJ, et al. Minimal contact treatment for smoking cessation. A placebo controlled trial of nicotine polacrilex and self-directed relapse prevention: initial results of the Stanford Stop Smoking Project. JAMA 1988; 260:1575-1580.

15. Fiore MC, Kenford SL, Jorenby DE, et al. Two studies of the clinical effectiveness of the nicotine patch with different counseling treatments. Chest 1994;105:524-533.

16. Glavas D, Rumboldt M, Rumboldt Z. Smoking cessation with nicotine replacement therapy among health care workers: randomized double-blind study. CroatMed J 2003;44:219-224.

17. Garvey AJ, Kinnunen T, Nordstrom BL, et al. Effects of nicotine gum dose by level of nicotine dependence. Nicotine Tob Res 2000;2:53-63.

18. Gonzales D, Rennard SI, Nides M, Oncken C, Azoulay S, Billing CB, Watsky EJ, Gong J, Williams KE, Reeves KR: Varenicline, an alpha4beta2 nicotinic acetylcholine receptor partial agonist, vs sustained -release Bupropion and placebo for smoking cessation: a randomized controlled trial. Jama 2006;296:47-55.

19. Gourlay SG, Forbes A, Marriner T, et al. Double blind trial of repeated treatment with transdermal nicotine for relapsed smokers. BMJ 1995;311:363-366.

20. Glover M. 1997. Smoking cessation services for Maori: advice on purchasing. Wellington: New Zealand CentralRegionalHealthAuthority. Available online at: http://www.ash.org.nz/pdf/Smoking/QuitSmoking/ MaoriCessatio.pdf Accessed: 11 November 2006.

21. Hughes J, Stead L, Lancaster T: Antidepressants for smoking cessation. Cochrane Database Syst Rev 2004, CD000031. 
22. Hughes JR, Gust SW, Keenan RM, et al. Nicotine vs placebo gum in general medical practice. JAMA 1989;261:1300-1305.

23. Hall SM, Humfleet GL, Reus VI, et al. Psychological intervention and anti depressant treatment in smoking cessation. Arch Gen Psychiatry 2002;59:930-936.

24. Holt S, Timu-Parata C, Ryder-Lewis S, et al. Efficacy of bupropion in the indigenous Maori population in New Zealand. Thorax 2005;60:120-123.

25. Hall SM, Munoz RF, Reus VI, et al. Mood management and nicotine gum in smoking treatment: a therapeutic contact and placebo-controlled study. J Consult Clin Psychol 1996;64:1003-1009.

26. Hjalmarson AI. Effect of nicotine chewing gum in smoking cessation. A randomized, placebo-controlled, double-blind study. JAMA 1984;252:2835-2838

27. Herrera N, Franco R, Herrera L, et al. Nicotine gum, 2 and $4 \mathrm{mg}$, for nicotine dependence. A double-blind placebo-controlled trial with in a behavior modification support program. Chest 1995;108:447-451.

28. Hall SM, Tunstall CD, Ginsberg D, et al. Nicotine gum and behavioral treatment: a placebo controlled trial. J Consult ClinPsychol1987;55:603-605.

29. Hays JT, Croghan IT, Schroeder DR, et al. Over-the-counter nicotine patch therapy for smoking cessation: results from randomized, double-blind, placebo-controlled, and open label trials. Am J Public Health 1999;89:1701-1707.

30. Hughes JR, Lesmes GR, Hatsukami DK, et al. Are higher doses of nicotine replacement more effective for smoking cessation? Nicotine Tob Res 1999;1:169-174.

31. Hurt RD, Dale LC, Fredrickson PA, et al. Nicotine patch therapy for smoking cessation combined with physician advice and nurse follow-up. One-year outcome and percentage of nicotine replacement. JAMA 1994;271:595-600.

32. Jorenby DE, Hays JT, Rigotti NA, Azoulay S, Watsky EJ, Williams KE, Billing CB, Gong J, Reeves KR. Efficacy of Varenicline, an alpha4beta2 nicotinic acetylcholine receptor partial agonist, vs placebo or sustaine-release Bupropion for smoking cessation: a randomized controlled trial. Jama 2006;296:56-63.

33. Jorenby DE, Leischow SJ, Nides MA, et al. A controlled trial of sustained-release bupropion, a nicotine patch, or both for smoking cessation. N Engl J Med 1999;340:685-691.

34. Jones L, Donnelly A, Harneiss C, Warbrick D, Swinn K, Malosi L, et al. A qualitative investigation of the application of behaviour modification to group-quitting for Maori and Pacific smokers. South Pacific Journal of Psychology. 2004;1:43-53.

35. Jarvik ME, Schneider NG. Degree of addiction and effectiveness of nicotine gum therapy for smoking. Am J Psychiatry 1984;141:790-791.

36. Jamrozik K, Fowler G, Vessey M, et al. Placebo controlled trial of nicotine chewing gum in general practice. Br Med J (Clin Res Ed) 1984; 289:794-797.

37. Jarvis MJ, Raw M, Russell MA, et al. Randomized controlled trial of nicotine chewing-gum. Br Med J (Clin Res Ed) 1982;285:537-540.

38. Killen JD, Fortmann SP, Newman B, et al. Evaluation of a treatment approach combining nicotine gum with selfguided behavioral treatments for smoking relapse prevention. J Consult ClinPsychol1990;58:85-92.

39. Kornitzer M, Boutsen M, Dramaix M, et al. Combined use of nicotine patch and gum in smoking cessation: a placebocontrolled clinical trial. Prev Med 1995;24:41-47.
40. Killen JD, Fortmann SP, Davis L, et al. Nicotine patch and self-help video for cigarette smoking cessation. J Consult ClinPsychol1997;65:663-672.

41. Law M, Tang JL: An analysis of the effectiveness of interventions intended to help people stop smoking. Arch Intern Med 1995, 155: 1933-1941.

42. Moore D, Aveyard P, Connock M, Wang D, Fry-Smith A, Barton P. Effectiveness and safety of Nicotine replacement therapy assisted reduction to stop smoking: Systematic review and meta-analyses. BMJ 2009;338:b1024.

43. Muramoto ML, Leischow SJ, Sherrill D, et al. Randomized, double-blind, placebo controlled trial of 2 dosages of sustained-release bupropion for adolescent smoking cessation. Arch Pediatr Adolesc Med 2007;161:1068-1074.

44. Ministry of Health. 2006. Tobacco Trends 2006: Monitoring tobacco use in New Zealand. Wellington: Ministry of Health. Available online at: http://www.moh.govt.nz/ moh.nsf/ by+unid/ 152B30631A C2E55DCC 2572450013FE5E?Open Accessed 14 February 2007.

45. Nakamura M, Oshima A, Fujimoto Y, et al. Efficacy and tolerability of varenicline, an alpha4 beta2 nicotinic acetylcholine receptor partial agonist, in a 12-week, randomized, placebo-controlled, dose-response study with 40-week follow-up for smoking cessation in Japanese smokers. ClinTher2007;29:1040-1056.

46. Malcolm RE, Sillett RW, Turner JA, et al. The use of nicotine chewing gum as an aid to stopping smoking. Psychopharmacology (Berl) 1980;70:295-296.

47. Nides M, Oncken C, Gonzales D, et al. Smoking cessation with Varenicline, a selective alpha4 beta2 nicotinic receptor partial agonist: results from a 7-week, randomized, placeboand Bupropion-controlled trial with 1-year follow-up. Arch InternMed2006;166:1561-1518.

48. Oncken C, Gonzales D, Nides M, et al. Efficacy and safety of the novel selective nicotinic acetylcholine receptor partial agonist, Varenicline, for smoking cessation.

49. Peto R, Lopez AD, Boreham J, Thun M, Heath C Jr, Doll R: Mortality from smoking worldwide. Br Med Bull 1996;52:12-21.

50. Paoletti P, Fornai E, Maggiorelli F, et al. Importance of baseline cotinine plasma values in smoking cessation: results from a double-blind study with nicotine patch. Eur Respir J 1996;9:643-651.

51. Randomized trial of nicotine patches in general practice: results at one year. Imperial Cancer Research Fund General Practice Research Group. BMJ 1994;308:1476-1477.

52. Richmond RL, Harris K, de Almeida NA. The transdermal nicotine patch: results of a randomised placebo-controlled trial. Med J Aust 1994;161:130-135.

53. Silagy C, Lancaster T, Stead L, Mant D, Fowler G. Nicotine replacement therapy for smoking cessation. Cochrane Database Syst Rev 2004;3:CD000146.

54. Stapleton J. Cigarette smoking prevalence, cessation and relapse. Stat Meth Med Res 1998;7187-7203.

55. Schneider NG, Jarvik ME, Forsythe AB, et al. Nicotine gum in smoking cessation: a placebo-controlled, double-blind trial. Addict Behav 1983;8:253-261.

56. Stapleton JA, Russell MA, Feyerabend C, et al. Dose effects and predictors of outcome in a randomized trial of transdermal nicotine patches in general practice. Addiction 1995;90:31.

57. Sachs DP, Sawe U, Leischow SJ. Effectiveness of a 16-hour transdermal nicotine patch in a medical practice setting, without intensive group counseling. Arch InternMed 1993;153:1881-90.

58. Tonstad S, Tonnesen P, Hajek P, Williams KE, Billing CB, Reeves KR: Effect of maintenance therapy with Varenicline 
on smoking cessation: a randomized controlled trial. Jama 2006, 296:64-71. Arch Intern Med 2006;166:1571-1517.

59. Tonnesen P, Fryd V, Hansen M, et al. Effect of nicotine chewing gum in combination with group counseling on the cessation of smoking. N Engl J Med 1988;318:15-18.

60. Tonnesen P, Paoletti P, Gustavsson G, et al. Higher dosage nicotine patches increase one-year smoking cessation rates: results from the European CEASE trial. Collaborative European Anti-Smoking Evaluation. European Respiratory Society. Eur Respir J 1999;13:238-246.
61. Transdermal nicotine for smoking cessation. Sixmonth results from two multicenter controlled clinical trials. Transdermal Nicotine Study Group. JAMA 1991;266:3133-3138.

62. Tonnesen P, Norregaard J, Simonsen K, et al. A double-blind trial of a 16-hour transdermal nicotine patch in smoking cessation. N Engl J Med 1991;325:311-315.

63. Westman EC, Levin ED, Rose JE. The nicotine patch in smoking cessation. A randomized trial with telephone counseling. Arch Intern Med 1993;153:1917-1923. 